Article

\title{
Prospective Observational Study to Evaluate the Effect of Different Levels of Positive End-Expiratory Pressure on Lung Mechanics in Patients with and without Acute Respiratory Distress Syndrome
}

\author{
Mascha O. Fiedler ${ }^{1}$, Dovile Diktanaite ${ }^{1,2,3}$, Emilis Simeliunas ${ }^{1,2,3}$, Maximilian Pilz ${ }^{4}$ (D) \\ and Armin Kalenka 2,5,* \\ 1 Department of Anesthesiology, Heidelberg University Hospital, 69120 Heidelberg, Germany; \\ mascha.fiedler@med.uni-heidelberg.de (M.O.F.); diktanaite@gmail.com (D.D.); simeliunui@gmail.com (E.S.) \\ 2 Department of Anesthesiology and Intensive Care Medicine, District Hospital Bergstrasse, \\ 64646 Heppenheim, Germany \\ 3 Department of Anesthesiology, Lucerne Hospital, 6000 Lucere, Switzerland \\ 4 Institute of Medical Biometry and Informatics, University of Heidelberg, 69120 Heidelberg, Germany; \\ pilz@imbi.uni-heidelberg.de \\ 5 Faculty of Medicine, University of Heidelberg, 69120 Heidelberg, Germany \\ * Correspondence: armin.kalenka@med.uni-heidelberg.de
}

Received: 30 June 2020; Accepted: 28 July 2020; Published: 31 July 2020

\begin{abstract}
Background: The optimal level of positive end-expiratory pressure is still under debate. There are scare data examining the association of PEEP with transpulmonary pressure (TPP), end-expiratory lung volume (EELV) and intraabdominal pressure in ventilated patients with and without ARDS. Methods: We analyzed lung mechanics in 3 patient groups: group A, patients with ARDS; group B, obese patients (body mass index (BMI) $>30 \mathrm{~kg} / \mathrm{m}^{2}$ ) and group C, a control group. Three levels of PEEP $\left(5,10,15 \mathrm{~cm} \mathrm{H}_{2} \mathrm{O}\right)$ were used to investigate the consequences for lung mechanics. Results: Fifty patients were included, 22 in group A, 18 in group B (BMI $38 \pm 2 \mathrm{~kg} / \mathrm{m}^{2}$ ) and 10 in group $\mathrm{C}$. At baseline, oxygenation showed no differences between the groups. Driving pressure $(\Delta \mathrm{P})$ and transpulmonary pressure $\left(\Delta \mathrm{P}_{\mathrm{L}}\right)$ was higher in group $\mathrm{B}$ than in groups $\mathrm{A}$ and $\mathrm{C}$ at a PEEP of $5 \mathrm{~cm} \mathrm{H}_{2} \mathrm{O}\left(\Delta \mathrm{P}\right.$ A: $15 \pm 1, \mathrm{~B}: 18 \pm 1, \mathrm{C}: 14 \pm 1 \mathrm{~cm} \mathrm{H}_{2} \mathrm{O} ; \Delta \mathrm{P}_{\mathrm{L}} \mathrm{A}: 10 \pm 1, \mathrm{~B}: 13 \pm 1$, C: $9 \pm 0 \mathrm{~cm} \mathrm{H}_{2} \mathrm{O}$ ). Peak inspiratory pressure ( $\left.P_{\text {insp }}\right)$ rose in all groups as PEEP increased, but the resulting driving pressure and transpulmonary pressure were reduced, whereas EELV increased. Conclusion: Measuring EELV or TPP allows a personalized approach to lung-protective ventilation.
\end{abstract}

Keywords: acute respiratory distress syndrome; lung physiology; mechanical ventilation; end-expiratory lung volume; esophageal pressure; transpulmonary pressure; lung injury; positive end-expiratory pressure

\section{Background}

Invasive ventilation, one of the most frequently applied strategies in the intensive care unit is often lifesaving. Nonetheless, it is a potentially harmful intervention that may lead to ventilator-induced lung injury (VILI) [1]. Causes of VILI are mainly stress, transpulmonary pressure (TPP) and strain and applied tidal volume $\left(\mathrm{V}_{\mathrm{T}}\right)$ in relation to end-expiratory lung volume (EELV) [2]. These two elements are not routinely measured at the bedside in patients with acute respiratory distress (ARDS) [3]. Therefore, most guidelines emphasize using lower $\mathrm{V}_{\mathrm{T}}(4-8 \mathrm{~mL} / \mathrm{kg}$ predicted body weight) and lower inspiratory pressures (plateau pressure $<28 \mathrm{~cm} \mathrm{H}_{2} \mathrm{O}$ ) [4,5] as well as a positive end-expiratory pressure (PEEP) based on oxygenation [6], as a standard of care. 
Although low tidal volume ventilation in patients with ARDS improves survival, when compared with high tidal volume [7], this difference between a low and intermediate tidal volume could not be detected in patients without ARDS [8]. Airway pressure alone may also be insufficient to guide lung-protective PEEP titration in ARDS. The contribution of chest wall and abdomen to pleural pressure and respiratory system mechanics is unpredictably in the critically ill patients $[9,10]$. Approximately $50 \%$ of the intra-abdominal pressure (IAP) is transmitted to the intrathoracic compartment [11]. Therefore, it has a direct impact on EELV and TPP.

Despite this, the relationship between transpulmonary pressure, lung volume and IAP in different types of patients with mechanical ventilation has not yet been fully explored.

We analyzed the relationship of EELV, lung mechanics and IAP in 3 patient groups: group A-patients with ARDS, group B-patients with obesity and group $\mathrm{C}$-a control group. Three levels of PEEP $\left(5,10,15 \mathrm{~cm} \mathrm{H}_{2} \mathrm{O}\right)$ were used to investigate the consequences of the different PEEP levels for lung mechanics. We hypothesized that an advanced measurement of EELV, TPP and IAP would allow an individualized titration of mechanical ventilation.

\section{Methods}

\subsection{Trial Design}

This project was performed in accordance with the Declaration of Helsinki and the approval of the local Ethics Committee of the Heidelberg Medical Faculty at the University of Heidelberg (S-579/2016; 15.02.2017), between April 2017 and January 2019, in the intensive care unit of Hospital Bergstrasse. The study protocol was registered in the German Clinical Trials Register (DRKS00012639). After providing appropriate information, written consent to study participation was obtained from the participating patients or their family members, which could be revoked without giving reasons.

All consecutive mechanically ventilated adult patients admitted who expected not to be extubated within $48 \mathrm{~h}$ were examined for possible inclusion in the study. The planed study protocol included measurements over a maximum of 3 days. Exclusion criteria were start of ventilation over $24 \mathrm{~h}$ previously, severe hemodynamic instability, higher grade of chronic obstructive lung disease (COPD) with GOLD grade 3 and 4, acute exacerbation of COPD, lung emphysema, pulmonary arterial hypertension, suspected elevated pulmonary arterial pressure in the echocardiography, application of a PEEP higher than $20 \mathrm{~cm} \mathrm{H}_{2} \mathrm{O}$, an inspired oxygen concentration $\left(\mathrm{F}_{\mathrm{i}} \mathrm{O}_{2}\right) \geq 0.8$, severe ARDS with a ratio between partial arterial pressure of oxygen to $\mathrm{F}_{\mathrm{i}} \mathrm{O}_{2}(\mathrm{P} / \mathrm{F}$ ratio $\left.)<100\right)$, an extracorporeal gas-exchange procedure (ECMO), use of high-frequency oscillation ventilation (HFOV) and abnormal airway anatomy due to partial lung resection or fistulas.

We predefined a priori cohorts as: Group A: patients with ARDS [12], group B: obese patients with the body mass index $(\mathrm{BMI})>30 \mathrm{~kg} / \mathrm{m}^{2}$ without ARDS, group C: a control group comprising patients suffering from cardiac arrest or with a neurological disease without ARDS or BMI $>30 \mathrm{~kg} / \mathrm{m}^{2}$.

All patients were ventilated in pressure-controlled mode with volume guaranty (Carescape R860, GE Healthcare, Madison, WI, USA) on the first day of the examination. Inspiratory pressure was controlled so that a tidal volume of $6 \mathrm{~mL} / \mathrm{kg}$ predicted body weight (pbw) was reached. It was verified that the respective patient had been in supine position for at least $15 \mathrm{~min}$ before the start of each measurement, in order to ensure identical examination conditions. Patients were sedated and paralyzed with $0.6 \mathrm{mg} / \mathrm{kg}$ pbw rocuronium bromide for the time indicated in the study protocol.

\subsection{Measurements and Calculations}

A polyethylene catheter (Nutrivent multifunction nasogastric catheter, Sidam, San Giacomo Roncole, Italy) was used to measure esophageal pressures. Appropriate catheter position was confirmed as previously described [13] with a non-stress minimal volume implementation [14]. Tidal volume $\left(\mathrm{V}_{\mathrm{T}}\right)$, Peak inspiratory airway pressure $\left(\mathrm{P}_{\text {Insp }}\right)$, PEEP, inspiratory esophageal pressure $\left(\mathrm{P}_{\text {EsInsp }}\right)$ and end-expiratory esophageal pressure $\left(\mathrm{P}_{\mathrm{EsExp}}\right)$ were recorded from the ventilator. Values for 
$\Delta \mathrm{P}$ and transpulmonary pressure $\left(\Delta \mathrm{P}_{\mathrm{L}}\right)$ were calculated as previously described [15]. Transpulmonary inspiratory pressure $\left(\mathrm{TPP}_{\text {Insp }}\right)$ was calculated as $\mathrm{TTP}_{\text {Insp }}=\mathrm{P}_{\text {Insp }}-\mathrm{P}_{\text {EsInsp }}$ and transpulmonary expiratory pressure $\left(\mathrm{TPP}_{\mathrm{Exp}}\right)$ as $\mathrm{TPP}_{\mathrm{Exp}}=\mathrm{PEEP}-\mathrm{P}_{\mathrm{EsExp}}$. Elastance of the respiratory system $\left(\mathrm{E}_{\mathrm{RS}}\right)$ was calculated as $E_{R S}=\left(P_{\text {Insp }}-P E E P\right) / V_{T}$, chest wall elastance $\left(E_{C W}\right)$ as $E_{C W}=\left(P_{\text {EsInsp }}-P_{\text {EsExp }}\right) / V_{T}$ and elastance of the lung $\left(E_{L}\right)$ as $E_{L}=E_{R S}-E_{C W}$. We measured EELV at the bedside as previously described without interrupting mechanical ventilation at the designated PEEP level [16]. We measured EELV as an absolute value as calculated by the ventilator. This absolute EELV was then normalized by dividing by the predicted body weight of the patient. $\mathrm{C}_{\text {Stat }}$ was measured by the ventilator during an inspiratory hold. End-expiratory IAP ( IAP $\left._{\text {Endex }}\right)$ was measured as recommended [17] and zeroed at the midaxillary level.

\subsection{Study Protocol}

The measurement of EELV, airway, esophageal and abdominal pressures at a PEEP of $15 \mathrm{~cm}$ $\mathrm{H}_{2} \mathrm{O}$ : The patient was ventilated for at least $15 \mathrm{~min}$ at a PEEP of $15 \mathrm{~cm} \mathrm{H}_{2} \mathrm{O}$. Achieving a steady-state situation by means of a stable carbon dioxide volume $\left(\mathrm{VCO}_{2}\right)$ for at least $10 \mathrm{~min}$ is essential for EELV measurement, as $\mathrm{VCO}_{2}$ is one of the main parameters for EELV calculation [16]. Therefore, patients with an extracorporeal $\mathrm{CO}_{2}$ elimination device were not included. EELV measurement was started on the R860 Carescape ventilator. The ventilator was equipped with a COVX module providing the data for EELV calculation. For EELV measurement, we used a stepwise change in $\mathrm{F}_{\mathrm{i}} \mathrm{O}_{2}$ of 0.2. EELV at each PEEP and measured this twice (wash-out and wash-in). At a $\mathrm{F}_{\mathrm{i}} \mathrm{O}_{2}$ increase of 0.2 , each complete wash-out and wash-in cycle took about 40 breaths; therefore, one measurement was completed within 10 min. Values for $\mathrm{P}_{\text {Insp }}, \mathrm{PEEP}, \mathrm{P}_{\text {EsInsp }}$ and $\mathrm{P}_{\text {EsExp }}$ were recorded from the ventilator. The $\mathrm{IAP}_{\text {Endex }}$ was measured in $\mathrm{mmHg}$ and converted into $\mathrm{cm}_{2} \mathrm{O}$.

After completion of the measurement program at a PEEP of $15 \mathrm{~cm} \mathrm{H}_{2} \mathrm{O}$, PEEP was reduced to $10 \mathrm{~cm} \mathrm{H}_{2} \mathrm{O}$, and inspiratory pressure was maintained to keep the tidal volume at $6 \mathrm{~mL} / \mathrm{kg} \mathrm{pbw}$. Measurements at a PEEP of $10 \mathrm{~cm} \mathrm{H}_{2} \mathrm{O}$ in analogy to PEEP $15 \mathrm{~cm} \mathrm{H}_{2} \mathrm{O}$ were followed by PEEP reduction to $5 \mathrm{~cm} \mathrm{H}_{2} \mathrm{O}$.

\subsubsection{Measurement Errors and Cancellations}

Respiratory reasons: drop of arterial oxygen saturation $>10 \%$, decrease in tidal volume $>20 \%$; cardio-circulatory reasons: drop of mean arterial pressure $>20 \%$, change in heart rate $>20 \%$; measurement error: if five consecutive measurements were aborted by the device, this was documented as a measurement error.

\subsubsection{Premature Study Exclusions}

Reasons for exclusion of a patient prior to planed study end at day 3: sufficient spontaneous breathing, extubation, death. Persistent hemodynamic instability preventing measurements for several consecutive days.

\subsection{Statistical Analysis}

The collected data were analyzed using SPSS software (IBM SPSS Statistics 25, Release 08.2015 IBM, Armonk, NY, USA) and the statistical software R, version 3.5 (R Foundation for Statistical Computing, Vienna, Austria). Mean values and standard deviations were calculated for quantitative variables. We analyzed data in the three groups with ANOVA, and in case of statistical differences, we used the independent $t$ test to capture the differences between three groups. We compared all groups in pairs: ARDS with obesity and then each group with the control group (A vs. B, B vs. C and A vs. C). We used the paired $t$ test to assess the change of lung parameters in the same group at the different levels of PEEP (PEEP 15 vs. $5 \mathrm{cmH}_{2} \mathrm{O}$ ). We used a linear mixed model to evaluate the influence of lung mechanics, intraabdominal pressure and body mass index on each of these. A linear mixed model is a more complex method for analyzing the correlation between the parameters than 
the "classical" Pearson correlation and can process diverse variables and include random and fixed effects. Since the patients were measured repeatedly, we chose the patient as a random effect and PEEP as well as the measurement number as fixed effects. For each comparison, the two variables to compare were included as outcome variable and fixed effect, respectively. The result of a mixed model is an effect value with a corresponding $p$-value. The larger the effect size and, thus, the smaller the $p$-value, the stronger is the relationship between the two variables of interest. For all statistical tests, the significance level was set at $p<0.05$. We used GraphPad PRISM 7 Software results (GraphPad Software, Inc., San Diego, CA, USA) for rerunning data and developing graphs, without differences in the statistical. The results are shown as mean \pm standard error of the mean (SEM).

\section{Results}

Between April 2017 and January 2019, we included 50 patients (mean age $68 \pm 13$; 31 males, 19 females) in the study. Twenty-two were mechanically ventilated because of ARDS and were enrolled in group A. Group B consisted of 18 obese patients but without ARDS. In group C (control) we enrolled 10 patients, who had neither ARDS nor were obese (Figure 1). Main baseline characteristics of patients at day 1 are presented in Table 1 . Weight and BMI were highest in Group B, with no differences between group $\mathrm{A}$ and C. Patients were ventilated with a $\mathrm{V}_{\mathrm{T}}$ between 6 and $7 \mathrm{~mL} / \mathrm{kg}$ pbw. P/F ratio was not significantly different in the three groups.

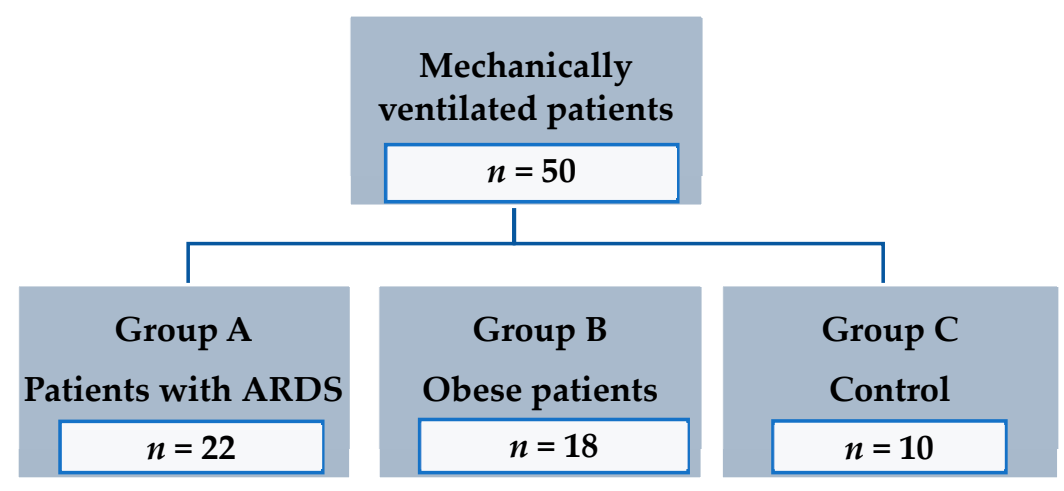

Figure 1. Flowchart displaying patients included in the study.

Respiratory mechanics measured in the study are presented in Table 2. Overall, we measured 399 values over time and at different PEEP levels $\left(5,10\right.$ and $\left.15 \mathrm{~cm} \mathrm{H}_{2} \mathrm{O}\right)$. This means that we had a drop out of 51 values ( 26 because of extubation, sufficient spontaneous breathing or death, 25 because of drop of arterial oxygen saturation $>10 \%$ or a decrease in tidal volume $>20 \%$ (Table S1). Peak inspiratory pressure, $\Delta \mathrm{P}$ and $\Delta \mathrm{P}_{\mathrm{L}}$ were higher in obese patients (group $\mathrm{B}$ ) compared to patients with ARDS (group $\mathrm{A}$ ). Although $\mathrm{P}_{\text {Insp }}$ and $\Delta \mathrm{P}$ did not differ between patients with ARDS patients and group $\mathrm{C}$ the resulting $\Delta \mathrm{P}_{\mathrm{L}}$ were significantly higher in group $\mathrm{A}$ than in group $\mathrm{C}$. Obese patients showed higher $\mathrm{P}_{\text {Insp }}, \Delta \mathrm{P}$ and $\Delta \mathrm{P}_{\mathrm{L}}$ than group $\mathrm{C}$. The EELV were lower in obese patients than in group $\mathrm{A}$ and $\mathrm{C}$. Although PEEP $15 \mathrm{~cm} \mathrm{H}_{2} \mathrm{O}$ in comparison to PEEP $5 \mathrm{~cm} \mathrm{H}_{2} \mathrm{O}$ increases $P_{\text {Insp }}$ in all groups, the resulting $\triangle \mathrm{P}$ and $\Delta \mathrm{P}_{\mathrm{L}}$ were significantly lower in all groups. The $\mathrm{E}_{\mathrm{RS}}$ and $\mathrm{E}_{\mathrm{L}}$ decreased with increasing PEEP in all groups, whereas $E_{C W}$ was unchanged. Obese patients had higher $E_{R S}, E_{L}$ and IAP than patients in Group A and C. Increasing PEEP had no influence on IAP but increased $\mathrm{P}_{\mathrm{EsExp}}$ in all groups. 
Table 1. Baseline characteristics of the study cohort.

\begin{tabular}{|c|c|c|c|}
\hline & $\begin{array}{c}\text { Group A }(n=22) \\
\text { Patients with ARDS }\end{array}$ & $\begin{array}{l}\text { Group B }(n=18) \\
\text { Obese Patients }\end{array}$ & $\begin{array}{c}\text { Group C }(n=10) \\
\text { Control }\end{array}$ \\
\hline \multicolumn{4}{|l|}{ Demographics } \\
\hline Age & $64 \pm 3$ & $72 \pm 3$ & $72 \pm 3$ \\
\hline Height (cm) & $173 \pm 2$ & $169 \pm 3$ & $175 \pm 2$ \\
\hline Weight (kg) & $87 \pm 4$ * & $107 \pm 6^{+}$ & $81 \pm 2$ \\
\hline $\mathrm{BMI}\left(\mathrm{kg} / \mathrm{m}^{2}\right)$ & $29 \pm 1$ * & $38 \pm 2^{+}$ & $27 \pm 1$ \\
\hline Male & $68 \%$ & $50 \%$ & $90 \%$ \\
\hline \multicolumn{4}{|l|}{$\begin{array}{c}\text { Cardiovascular } \\
\text { presentation }\end{array}$} \\
\hline MAD (mmHg) & $78 \pm 2$ & $76 \pm 2^{+}$ & $84 \pm 3$ \\
\hline HR (bpm) & $85 \pm 4$ & $85 \pm 3$ & $87 \pm 4$ \\
\hline $\mathrm{S}_{\mathrm{p}} \mathrm{O}_{2}(\%)$ & $96 \pm 1^{\#}$ & $98 \pm 0$ & $98 \pm 0$ \\
\hline etCO $2(\mathrm{mmHg})$ & $42 \pm 1^{\#}$ & $41 \pm 1$ & $37 \pm 2$ \\
\hline $\begin{array}{l}\text { Norepinephrine } \\
\mu \mathrm{g} / \mathrm{kgKG} / \mathrm{min}\end{array}$ & $0.24 \pm 0.05$ & $0.17 \pm 0.03$ & $0.24 \pm 0.06$ \\
\hline \multicolumn{4}{|l|}{$\begin{array}{l}\text { Ventilatory } \\
\text { parameter }\end{array}$} \\
\hline $\mathrm{F}_{\mathrm{i}} \mathrm{O}_{2}(\%)$ & $44 \pm 2 * \#$ & $39 \pm 1$ & $38 \pm 1$ \\
\hline $\mathrm{V}_{\mathrm{T}}(\mathrm{mL})$ & $424 \pm 6$ & $414 \pm 6$ & $433 \pm 6$ \\
\hline $\mathrm{V}_{\mathrm{T}}(\mathrm{mL} / \mathrm{kg} \mathrm{pbw})$ & $6 \pm 0 *$ & $7 \pm 0^{+}$ & $6 \pm 0$ \\
\hline $\mathrm{RR}(/ \mathrm{min})$ & $19 \pm 0$ \# & $19 \pm 0^{+}$ & $18 \pm 0$ \\
\hline $\mathrm{MV}(\mathrm{L} / \mathrm{min})$ & $9 \pm 0$ & $9 \pm 0$ & $8 \pm 0$ \\
\hline $\operatorname{PEEP}\left(\mathrm{cmH}_{2} \mathrm{O}\right)$ & $14 \pm 1^{\#}$ & $15 \pm 1^{+}$ & $11 \pm 1$ \\
\hline $\mathrm{P}_{\text {Insp }}\left(\mathrm{cmH}_{2} \mathrm{O}\right)$ & $27 \pm 1^{*, \#}$ & $30 \pm 1^{+}$ & $24 \pm 1$ \\
\hline$\Delta \mathrm{P}\left(\mathrm{cmH}_{2} \mathrm{O}\right)$ & $12 \pm 1 *$ & $15 \pm 1$ & $13 \pm 0$ \\
\hline $\begin{array}{l}\mathrm{C}_{\text {Stat }}\left(\mathrm{cmH}_{2} \mathrm{O}\right) \text { at } \\
\text { PEEP } 5\left(\mathrm{cmH}_{2} \mathrm{O}\right)\end{array}$ & $60 \pm 20$ & $58 \pm 22$ & $62 \pm 23$ \\
\hline \multicolumn{4}{|l|}{ Gas exchange } \\
\hline $\mathrm{pH}$ & $7,3 \pm 0^{\#}$ & $7,3 \pm 0^{+}$ & $7,4 \pm 0$ \\
\hline $\mathrm{p}_{\mathrm{a}} \mathrm{CO}_{2}(\mathrm{mmHg})$ & $59 \pm 2 *$,\# & $51 \pm 2$ & $50 \pm 2$ \\
\hline $\mathrm{p}_{\mathrm{a}} \mathrm{O}_{2}(\mathrm{mmHg})$ & $93 \pm 3^{*}$ & $106 \pm 3$ & $96 \pm 5$ \\
\hline $\mathrm{P} / \mathrm{F}$ ratio & $210 \pm 18$ & $244 \pm 15$ & $232 \pm 11$ \\
\hline
\end{tabular}

$\mathrm{BMI}=$ = body mass index; MAD = mean arterial pressure; $\mathrm{mmHg}=$ millimeter of mercury; $\mathrm{HR}=$ Heart rate; bpm = beats per minute; $\mathrm{S}_{\mathrm{p}} \mathrm{O}_{2}=$ saturation of oxygen; etCO $\mathrm{C}_{2}=$ end-expiratory carbon dioxide; $\mathrm{F}_{\mathrm{i}} \mathrm{O}_{2}=$ inspired oxygen concentration; $\mathrm{V}_{\mathrm{T}}=$ tidal volume; $\mathrm{pbw}=$ predicted body weight; $\mathrm{RR}=$ respiratory rate; $\mathrm{MV}=$ minute ventilation; $\mathrm{PEEP}=$ positive end-expiratory pressure; $\mathrm{P}_{\text {insp }}=$ peak inspiratory pressure; $\Delta \mathrm{P}=$ driving pressure; $\mathrm{C}_{\text {Stat }}=$ static lung compliance; $\mathrm{p}_{\mathrm{a}} \mathrm{CO}_{2}=$ partial arterial pressure of carbon dioxide; $\mathrm{p}_{\mathrm{a}} \mathrm{O}_{2}=$ partial arterial pressure of oxygen; $\mathrm{P} / \mathrm{F}$ ratio $=$ ratio between partial arterial pressure of oxygen to $\mathrm{F}_{\mathrm{i}} \mathrm{O}_{2} .{ }^{*} p<0.05$ group A vs. group $\mathrm{B}$, ${ }^{\#} p<0.05$ group $\mathrm{A}$ vs. group $\mathrm{C},{ }^{+} p<0.05$ group $\mathrm{B}$ vs. group $\mathrm{C}$. 
Table 2. Respiratory mechanics with positive end-expiratory pressure (PEEP) 5, 10 and $15 \mathrm{cmH}_{2} \mathrm{O}$.

\begin{tabular}{|c|c|c|c|c|}
\hline & PEEP & $\begin{array}{c}\text { Group A }(n=22) \\
\text { Patients with ARDS }\end{array}$ & $\begin{array}{c}\text { Group B }(n=18) \\
\text { Obese Patients }\end{array}$ & $\begin{array}{c}\text { Group C }(n=10) \\
\text { Control }\end{array}$ \\
\hline \multicolumn{5}{|l|}{ Respiratory mechanics } \\
\hline \multirow[t]{3}{*}{$\mathrm{P}_{\text {Insp }}\left(\mathrm{cm} \mathrm{H}_{2} \mathrm{O}\right)$} & 5 & $20 \pm 1^{*}$ & $23 \pm 1^{+}$ & $19 \pm 1$ \\
\hline & 10 & $23 \pm 0 *$ & $25 \pm 1^{+}$ & $22 \pm 0$ \\
\hline & 15 & $28 \pm 0 *$, & $30 \pm 0^{+, \S}$ & $27 \pm 1^{\S}$ \\
\hline \multirow[t]{3}{*}{$\Delta \mathrm{P}\left(\mathrm{cm} \mathrm{H}_{2} \mathrm{O}\right)$} & 5 & $15 \pm 1 *$ & $18 \pm 1^{+}$ & $14 \pm 1$ \\
\hline & 10 & $13 \pm 0^{*}$ & $15 \pm 1^{+}$ & $12 \pm 0$ \\
\hline & 15 & $13 \pm 0 * \S$ & $15 \pm 0^{+, \S}$ & $12 \pm 0 \S$ \\
\hline \multirow[t]{3}{*}{$\Delta \mathrm{P}_{\mathrm{L}}\left(\mathrm{cm} \mathrm{H}_{2} \mathrm{O}\right)$} & 5 & $10 \pm 1 * \#$ & $13 \pm 1^{+}$ & $9 \pm 0$ \\
\hline & 10 & $9 \pm 0 * \#$ & $10 \pm 0^{+}$ & $7 \pm 0$ \\
\hline & 15 & $9 \pm 0 * \#, \S$ & $10 \pm 0^{+, \S}$ & $7 \pm 0^{\S}$ \\
\hline \multirow[t]{3}{*}{$\mathrm{TPP}_{\operatorname{Exp}}\left(\mathrm{cm} \mathrm{H}_{2} \mathrm{O}\right)$} & 5 & $-5 \pm 1^{*}$ & $-8 \pm 1^{+}$ & $-6 \pm 1$ \\
\hline & 10 & $-2 \pm 1 *$ & $-4 \pm 0^{+}$ & $-3 \pm 1$ \\
\hline & 15 & $1 \pm 0 *, \S$ & $-1 \pm 0^{+, \S}$ & $1 \pm 0^{\S}$ \\
\hline \multirow[t]{3}{*}{$\mathrm{TPP}_{\text {Insp }}\left(\mathrm{cm} \mathrm{H}_{2} \mathrm{O}\right)$} & 5 & $5 \pm 0^{\#}$ & $5 \pm 1$ & $4 \pm 0$ \\
\hline & 10 & $7 \pm 0^{\#}$ & $6 \pm 0$ & $5 \pm 0$ \\
\hline & 15 & $10 \pm 1^{\#, \S}$ & $9 \pm 0 \S$ & $8 \pm 1 \S$ \\
\hline \multirow[t]{3}{*}{$\mathrm{P}_{\text {EsExp }}\left(\mathrm{cm} \mathrm{H}_{2} \mathrm{O}\right)$} & 5 & $10 \pm 1 *$ & $13 \pm 1^{+}$ & $11 \pm 1$ \\
\hline & 10 & $12 \pm 1^{*}$ & $14 \pm 1^{+}$ & $13 \pm 1$ \\
\hline & 15 & $14 \pm 0 * \S$ & $16 \pm 0^{+, \S}$ & $14 \pm 0 \S$ \\
\hline \multirow[t]{3}{*}{ EELV (ml) } & 5 & $1242 \pm 85$ & $1181 \pm 64^{+}$ & $1440 \pm 101$ \\
\hline & 10 & $1541 \pm 108^{\#}$ & $1452 \pm 73^{+}$ & $1880 \pm 138$ \\
\hline & 15 & $1850 \pm 119^{\#, \S}$ & $1915 \pm 97^{+, \S}$ & $2214 \pm 154 \S$ \\
\hline \multirow[t]{3}{*}{ EELV (ml/kg pbw) } & 5 & $18 \pm 1^{\#}$ & $19 \pm 1$ & $21 \pm 1$ \\
\hline & 10 & $22 \pm 1^{\#}$ & $23 \pm 1$ & $27 \pm 2$ \\
\hline & 15 & $27 \pm 1 *, \S$ & $31 \pm 1^{\S}$ & $30 \pm 2 \S$ \\
\hline \multirow[t]{3}{*}{$\mathrm{E}_{\mathrm{RS}}\left(\mathrm{cm} \mathrm{H} \mathrm{H}_{2} \mathrm{O} / \mathrm{mL}\right)$} & 5 & $32 \pm 3^{*}$ & $42 \pm 5^{+}$ & $36 \pm 6$ \\
\hline & 10 & $30 \pm 1 *$ & $38 \pm 2^{+}$ & $28 \pm 1$ \\
\hline & 15 & $31 \pm 1 * \S$ & $36 \pm 1^{+, \S}$ & $29 \pm 1 \S$ \\
\hline \multirow[t]{3}{*}{$\mathrm{E}_{\mathrm{L}}\left(\mathrm{cm} \mathrm{H} \mathrm{H}_{2} \mathrm{O} / \mathrm{mL}\right)$} & 5 & $24 \pm 3^{*}$ & $32 \pm 5^{+}$ & $22 \pm 3$ \\
\hline & 10 & $21 \pm 1 * \#$ & $26 \pm 1^{+}$ & $17 \pm 1$ \\
\hline & 15 & $21 \pm 1 * \#, \S$ & $24 \pm 1^{+, \S}$ & $17 \pm 1^{\S}$ \\
\hline \multirow[t]{3}{*}{$\mathrm{E}_{\mathrm{CW}}\left(\mathrm{cm} \mathrm{H} \mathrm{H}_{2} \mathrm{O} / \mathrm{mL}\right)$} & 5 & $10 \pm 1^{*}$ & $12 \pm 1$ & $11 \pm 1$ \\
\hline & 10 & $10 \pm 0 *$ & $12 \pm 0$ & $11 \pm 0$ \\
\hline & 15 & $11 \pm 1$ & $12 \pm 1$ & $12 \pm 1$ \\
\hline \multirow[t]{3}{*}{$\mathrm{IAP}\left(\mathrm{cm} \mathrm{H}_{2} 0\right)$} & 5 & $8 \pm 0 *$ & $11 \pm 0^{+}$ & $9 \pm 0$ \\
\hline & 10 & $8 \pm 0 *$ & $11 \pm 0^{+}$ & $9 \pm 0$ \\
\hline & 15 & $8 \pm 0 *$ & $11 \pm 0^{+}$ & $9 \pm 0$ \\
\hline
\end{tabular}

$\mathrm{P}_{\text {Insp }}=$ peak inspiratory pressure; $\Delta \mathrm{P}=$ driving pressure; $\Delta \mathrm{P}_{\mathrm{L}}=$ transpulmonary pressure gradient; $\mathrm{TPP}_{\mathrm{Exp}}=$ expiratory transpulmonary pressure; $\mathrm{TPP}_{\text {Insp }}=$ inspiratory transpulmonary pressure; $\mathrm{P}_{\mathrm{EsExp}}=$ end-expiratory esophageal pressure; $\mathrm{EELV}=$ end-expiratory lung volume; $\mathrm{EELV} / \mathrm{kg}$ = end-expiratory lung volume per kg bodyweight; $\mathrm{E}_{\mathrm{RS}}=$ elastance of the respiratory system; $\mathrm{E}_{\mathrm{L}}=$ lung elastance; $\mathrm{E}_{\mathrm{CW}}=$ elastance of the chest wall; IAP $=$ intraabdominal pressure; ${ }^{*} p<0.05$ group A vs. group $\mathrm{B},{ }^{\#} p<0.05$ group A vs. group $\mathrm{C}^{+} p<0.05$ group B vs. group C. $\S^{\S}<0.05$ PEEP 5 vs. PEEP 15. 


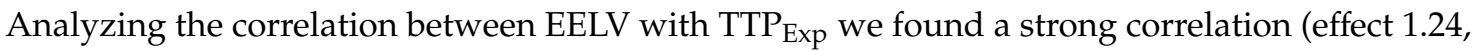
CI 95\% $(1.091 ; 1.399), p<0.01)$ (Figure 2$)$ and a negative correlation to $\Delta \mathrm{P}_{\mathrm{L}}$ (effect $-0.98, \mathrm{CI} 95 \%(-1.244$; $-0.724), p<0.01$ ) (Figure 3). The IAP and BMI correlate significantly with $\mathrm{P}_{\text {EsExp }}$ (effect 0.175, CI (0.112; $0.238), p<0.01$ for IAP and effect 0.26 , CI 95\% (0.161; 0.355), $p<0.01$ for BMI) (Figures 4 and 5 ). We found no significant correlation between IAP and $\mathrm{E}_{\mathrm{CW}}$ or between $\mathrm{BMI}$ and $\mathrm{E}_{\mathrm{CW}}$. The $\Delta \mathrm{P}_{\mathrm{L}}$ was strongly correlation with $\Delta \mathrm{P}$ (effect $0.97, \mathrm{CI} 95 \%(0.931 ; 1.01), p<0.01)$ (Figure 6$)$.

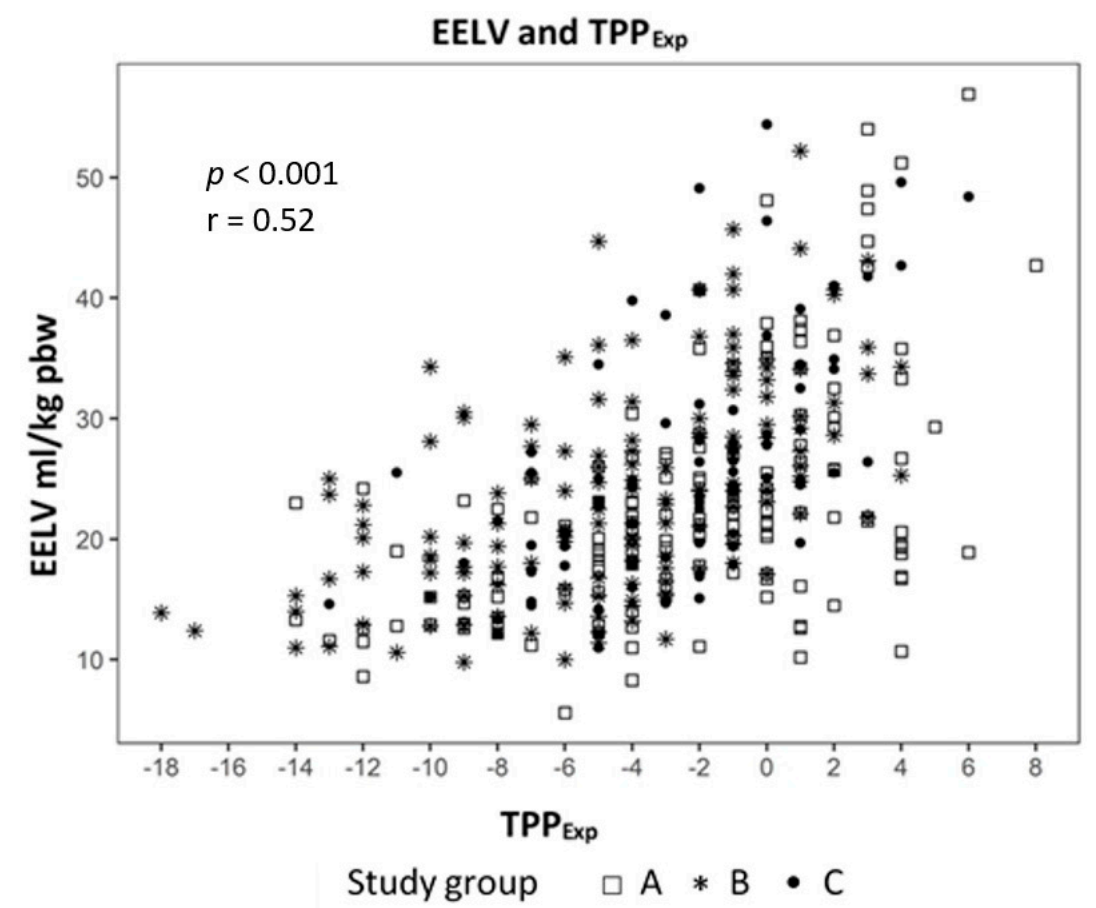

Figure 2. Correlation between end-expiratory lung volume (EELV) and transpulmonary expiratory pressure $\left(\mathrm{TPP}_{\operatorname{Exp}}\right)$.

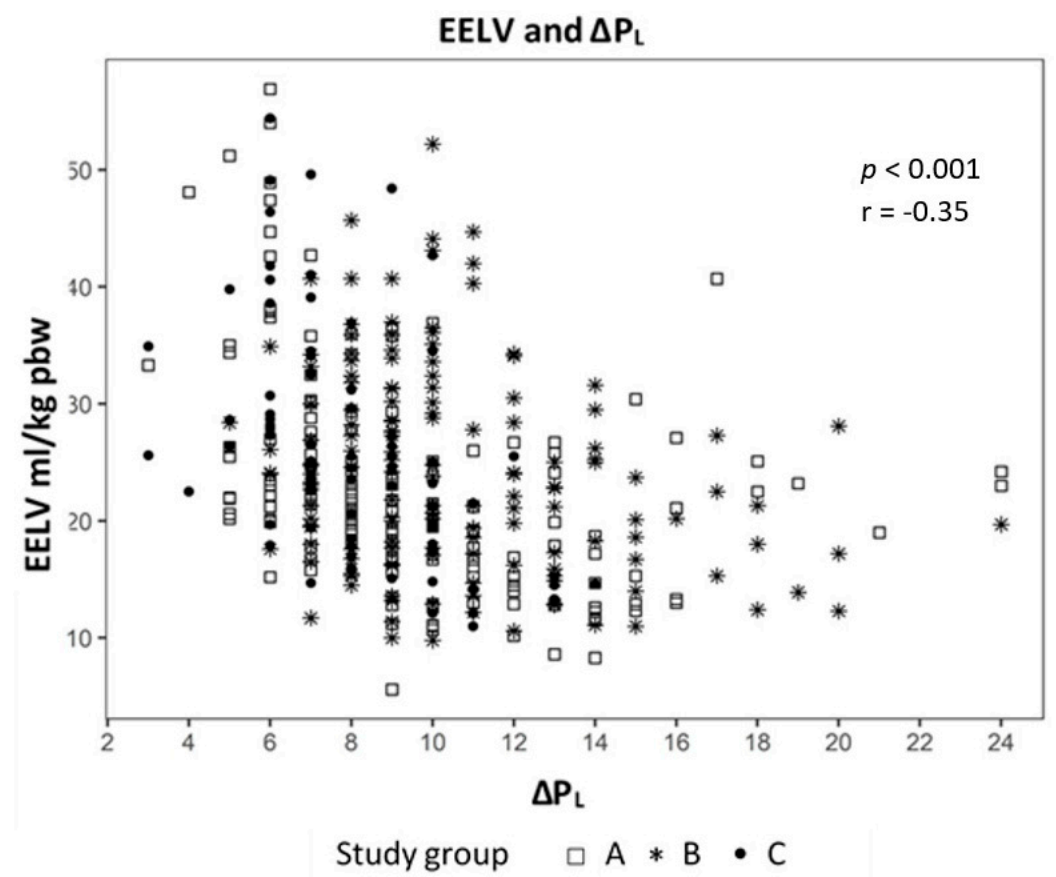

Figure 3. Correlation between end-expiratory lung volume (EELV) and transpulmonary pressure $\left(\Delta \mathrm{P}_{\mathrm{L}}\right)$. 


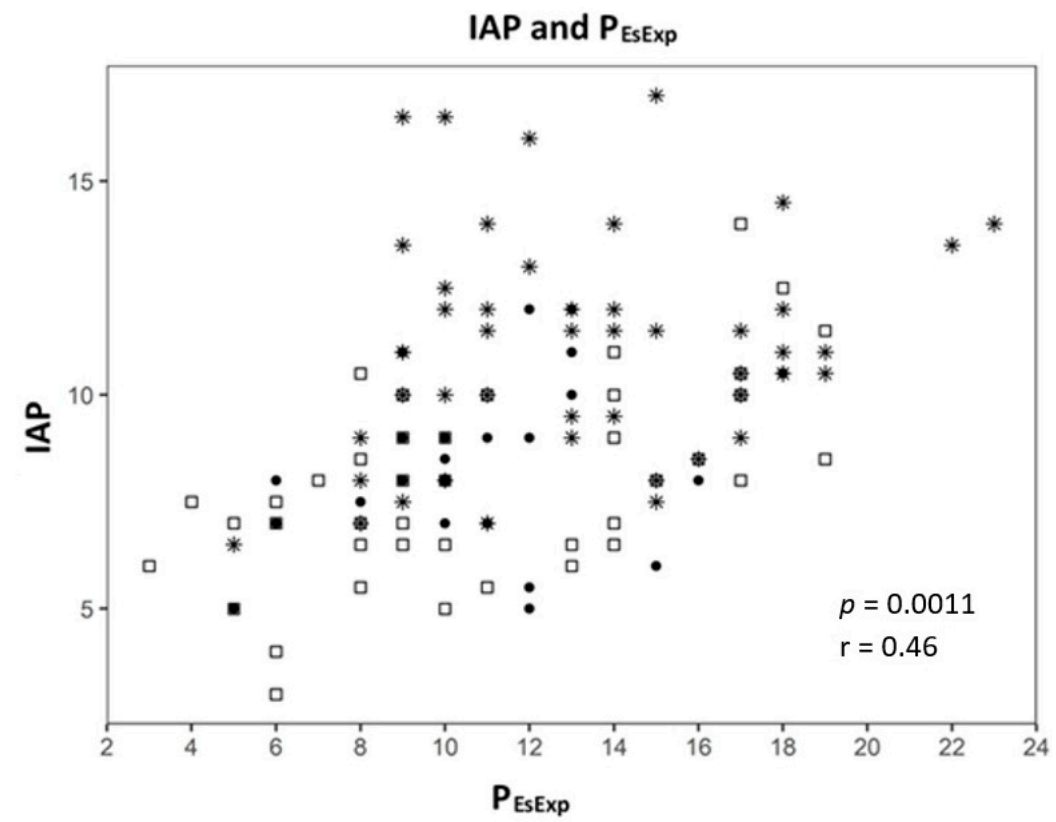

Study group $\square \mathrm{A} * \mathrm{~B} \cdot \mathrm{C}$

Figure 4. Correlation between intra-abdominal pressure (IAP) and transpulmonary expiratory pressure $\left(\mathrm{P}_{\text {EsExp }}\right)$.

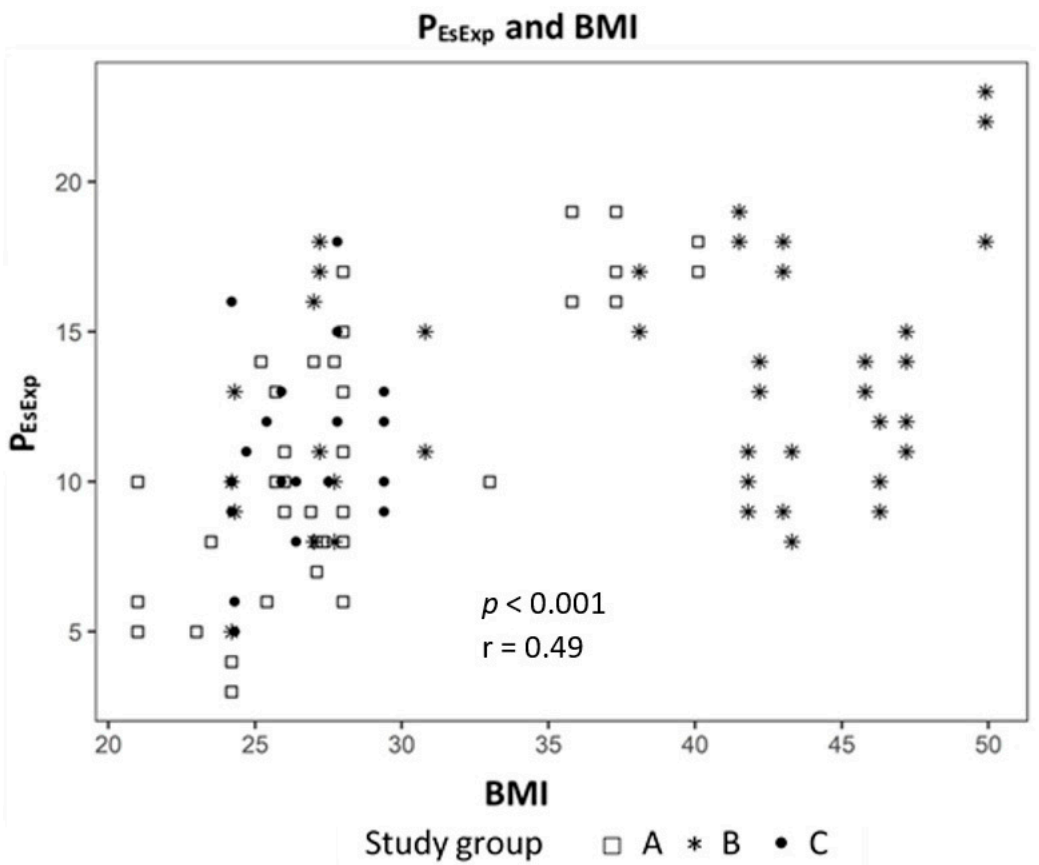

Figure 5. Correlation between body mass index (BMI) and transpulmonary expiratory pressure ( $\left.\mathrm{P}_{\operatorname{EsExp}}\right)$. 


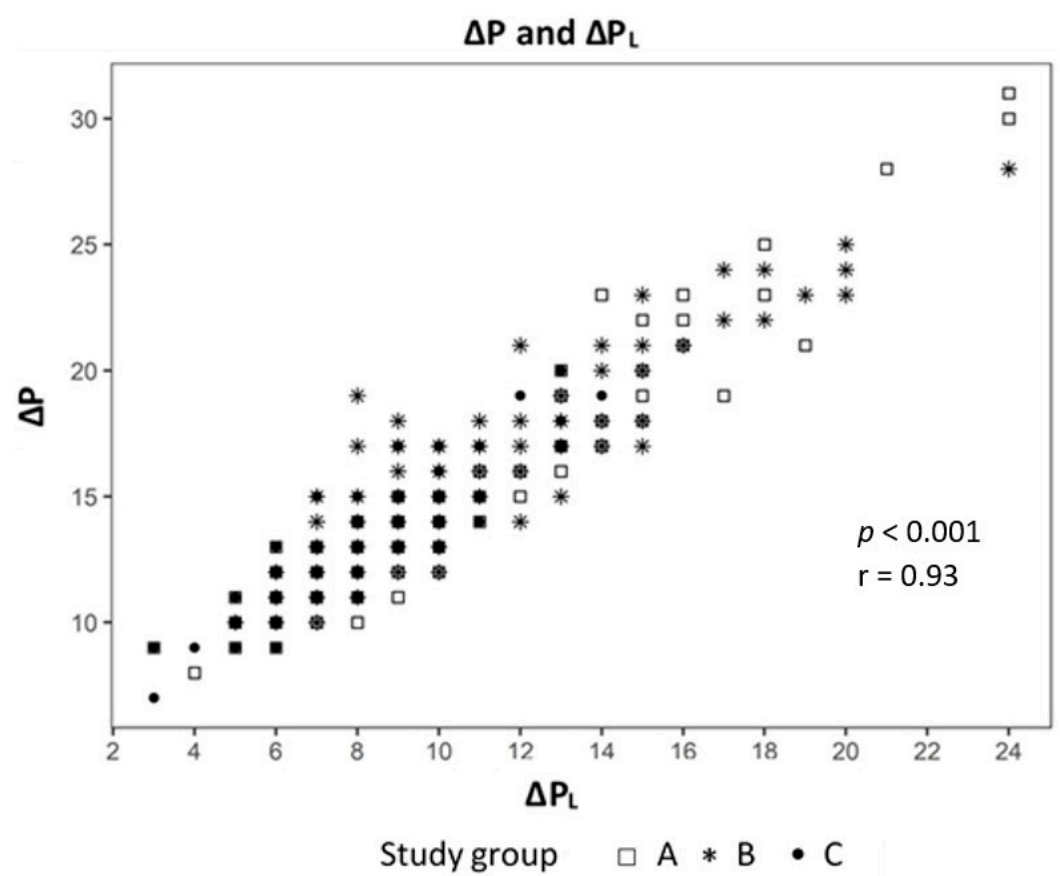

Figure 6. Correlation between driving pressure $(\Delta \mathrm{P})$ and transpulmonary pressure $\left(\Delta \mathrm{P}_{\mathrm{L}}\right)$.

\section{Discussion}

The main findings of this study are that (1) even patients without ARDS show severe impairment of lung mechanics, (2) this cannot be ruled out by assessing oxygenation and (3) measurements of EELV or $\Delta \mathrm{P}_{\mathrm{L}}$ allow an individualized approach of PEEP management.

We were not targeting the most severe patients. By definition, patients with ARDS fulfilled the criteria for a mild situation. According to the ARDS network table, PEEP would be around $5 \mathrm{~cm}_{2} \mathrm{O}$. In the other two groups, $\mathrm{P} / \mathrm{F}$ ratios were relatively similar to the ARDS group. Although $\mathrm{P} / \mathrm{F}$ ratio in our three groups did not differ, we found significant differences between the groups in absolute EELV as well as EELV $/ \mathrm{kg}$ pbw and $\Delta \mathrm{P}$ and $\Delta \mathrm{P}_{\mathrm{L}}$. One clinical feature of ARDS is atelectrauma, which could not be identified by arterial oxygenation in an ARDS experimental model of ARDS [18]. Intratidal recruitment and derecruitment of alveolar structures lead to shear stress [19]. This alveolar instability contributes to early ventilator-induced lung injury and can be attenuated by appropriate PEEP [20]. By increasing the PEEP up to $15 \mathrm{~cm} \mathrm{H}_{2} \mathrm{O}, \Delta \mathrm{P}$ and $\Delta \mathrm{P}_{\mathrm{L}}$ were reduced, and impaired EELV could be optimized in all groups, suggesting potential for recruitment effects. This lung recruitment can reduce mechanical stress resulting from inhomogeneities in the lung, acting as stress raisers [21].

The optimal approach to titrate PEEP is still under debate in patients with ARDS [22] and even more unclear in patients without ARDS. A variety of bedside tools to titrate PEEP exist such as oxygenation response to PEEP [23], change in driving pressure $(\Delta \mathrm{P})$ [24], esophageal pressure [9] or lung recruitment/hyperinflation assessed with the electrical impedance tomography [25]. Such individualized ventilation protocols can improve the outcome in patients with ARDS [26] and in severely obese patients [27], as compared to the standard of care.

Global lung mechanics, e.g., airway pressure, provides a poor surrogate of alveolar dynamics during mechanical ventilation [28]. Apart from that, inspiratory pressures are inaccurate surrogates of true transalveolar stretch, as they do not take into consideration the contribution of the chest wall to respiratory system compliance [1]. Available data suggest that decreased driving pressure in ARDS patients improves the outcome of lung-protective ventilation [24,29]. Interestingly, a study has shown that $\triangle \mathrm{P}$ has no impact on mortality in obese ARDS patients [30]. However, there are limited data on driving pressure in patients without ARDS. Recently, a secondary analysis of the Lung-Protective Ventilation Initiated in the Emergency Department (LOV-ED) trial found that in patients without ARDS, driving pressure is a risk factor for mortality and the development of ARDS [31]. In this 
study, esophageal pressures were not recorded, so transpulmonary pressure could not be calculated. Interestingly, these patients had a $\mathrm{T}_{\mathrm{V}}$ of $8.0 \mathrm{~mL} / \mathrm{kg}$ pbw and a PEEP of only $5 \mathrm{~cm} \mathrm{H}_{2} \mathrm{O}$. This is quite different from our patients without ARDS. We used a much higher PEEP and aimed for a $V_{T}$ of $6 \mathrm{~mL} / \mathrm{kg}$ pbw. Although in all groups $\mathrm{P}_{\text {Insp }}$ increased with higher PEEP, in groups $\mathrm{A}$ and $\mathrm{B}$ even up to $28 \mathrm{~cm}$ $\mathrm{H}_{2} \mathrm{O}$, the resulting $\triangle \mathrm{P}$ was lower with the higher PEEP.

Reduction of EELV is a typical feature of ARDS [32]. This phenomenon is attributed to alveolar collapse. We found similar impairment of EELV in our group of moderately obese patients. A physiological study with obese patients (BMI $48 \mathrm{~km} / \mathrm{m}^{2}$ ) found that negative $\operatorname{TPP}_{\text {Exp }}$ is responsible for alveolar collapse [33]. In severely obese patients (BMI almost $60 \mathrm{~kg} / \mathrm{m}^{2}$ ), titration of PEEP according to the $\mathrm{PEEP} / \mathrm{F}_{\mathrm{i}} \mathrm{O}_{2}$ table resulted in a low $\mathrm{P} / \mathrm{F}$ ratio, elevated driving pressure and impaired lung compliance [34]. On the other hand, applied PEEP may also contribute to VILI by over-distending aerated lung areas. In these critically ill obese patients with ARDS, titration of PEEP according to the best lung function decreased lung overdistension and alveolar collapse assessed by the electrical lung tomography [34]. The optimal PEEP was found with $\mathrm{TPP}_{\text {Exp }}$, which was slightly positive at $1 \mathrm{~cm}$ $\mathrm{H}_{2} \mathrm{O}$. In our study, BMI was much lower but showed exactly the same physiological alterations with reduced EELV and high $\triangle \mathrm{P}$. In our obese patients $\mathrm{TPP}_{\mathrm{Exp}}$ values were still negative even with a PEEP of $15 \mathrm{~cm} \mathrm{H}_{2} \mathrm{O}$. Although with a PEEP of $15 \mathrm{~cm} \mathrm{H}_{2} \mathrm{O}$, we obtained significantly better EELV and EELV/kg pbw, we could not rule out that much higher PEEP levels might be even more protective. Recent recommendations emphasize accepting plateau pressure higher than $30 \mathrm{~cm} \mathrm{H}_{2} \mathrm{O}$ in this context [35]. Interestingly, even in the non-ARDS and non-Obese group, $\mathrm{TPP}_{\operatorname{Exp}}$ was negative at a PEEP of $5 \mathrm{~cm}$ $\mathrm{H}_{2} \mathrm{O}$ in our study.

We used a linear mixed model to evaluate the influence of lung mechanics, intraabdominal pressure and body mass index. The analysis showed a strong positive correlation between EELV and $\mathrm{TTP}_{\mathrm{Exp}}$ and a negative correlation with $\Delta \mathrm{P}_{\mathrm{L}}$. This means that higher EELV leads to lower $\Delta \mathrm{P}_{\mathrm{L}}$, one cause of VILI, in our study. The $\Delta \mathrm{P}_{\mathrm{L}}$ had a strong correlation to $\Delta \mathrm{P}$, which may mean that driving pressure is a parameter of lung mechanics, which is just as accurate, yet more measurable as $\Delta \mathrm{P}_{\mathrm{L}}$, which only can be measured with an esophageal catheter.

In all three groups, $E_{R S}$ and $E_{L}$ decreased with increasing PEEP, but $E_{C W}$ remained the same in all groups. This was most probably due to the best compliance and the lowest $\mathrm{E}_{\mathrm{L}}$ with the PEEP increasing up to $15 \mathrm{~cm} \mathrm{H}_{2} \mathrm{O}$. Furthermore, we found a positive correlation between BMI and IAP with $\mathrm{P}_{\text {EsEndexp }}$ in our study. No correlation could be found between BMI and IAP with $\mathrm{E}_{\mathrm{CW}}$. These findings are in line with the studies in patients with ARDS. Krebs et al. applied different PEEP levels (up to $20 \mathrm{cmH}_{2} \mathrm{O}$ ) in 20 patients with ARDS; one half of this group had elevated IAP, and the other half did not (with a mean IAP of 16 and $8 \mathrm{mmHg}$, respectively) [36]. PEEP was found to decrease $\mathrm{E}_{\mathrm{RS}}$ by decreasing $E_{\mathrm{L}}$ without influencing $\mathrm{E}_{\mathrm{CW}}$ in both groups. These findings could explain the fact that patients with higher BMI and elevated IAP are at risk for developing atelectasis, which is one of the major components for VILI, so they may profit from an individual PEEP management approach.

\section{Limitations}

Some limitations in our study must be addressed. First, the study population is relatively small, and we did not analyze outcomes in these cohorts. The physicians at the bedside were not blinded, so that might lead to relative high PEEP even in the non-ARDS groups. We measured P/F ratio on the designated PEEP level and not on a standardized PEEP level of $5 \mathrm{~cm} \mathrm{H}_{2} \mathrm{O}$. We analyzed only PEEP from 5 to $15 \mathrm{~cm} \mathrm{H}_{2} \mathrm{O}$ and therefore cannot rule out that even higher PEEP may be optimal.

\section{Conclusions}

Lung mechanics are significantly impaired in ARDS and non-ARDS patients. Combinations of PEEP and $\mathrm{F}_{\mathrm{I}} \mathrm{O}_{2}$ to maintain targeted saturation (88-95\%) or $\mathrm{P}_{\mathrm{a}} \mathrm{O}_{2}(55-80 \mathrm{~mm} \mathrm{Hg})$, which are used in the ARDS Network studies, do not address individual lung mechanics. With an individualized 
approach, measurements of TPP and EELV seem to be reasonable and allow a better lung protective approach even in non-ARDS patients.

Supplementary Materials: The following are available online at http://www.mdpi.com/2077-0383/9/8/2446/s1, Table S1: Lung mechanics per day and PEEP.

Author Contributions: M.O.F., D.D. and A.K. designed the study, collected the data, interpreted the analyses and wrote the first draft of the manuscript. E.S. and M.P. helped to collect the data and reviewed the manuscript. All authors have read and agreed to the published version of the manuscript.

Funding: The study itself was funded by the Hospital Bergstrasse.

Conflicts of Interest: M.O.F. has received speakers fee and travel costs from Löwenstein Medical. A.K. has received speakers fee and travel costs from GE Healthcare, Getinge and Löwenstein Medical. The other authors report no conflicts of interest.

\section{References}

1. Slutsky, A.S.; Ranieri, V.M. Ventilator-induced lung injury. N. Engl. J. Med. 2013, 369, 2126-2136. [CrossRef] [PubMed]

2. Protti, A.; Cressoni, M.; Santini, A.; Langer, T.; Mietto, C.; Febres, D.; Chierichetti, M.; Coppola, S.; Conte, G.; Gatti, S.; et al. Lung stress and strain during mechanical ventilation: Any safe threshold? Am. J. Respir. Crit. Care Med. 2011, 183, 1354-1362. [CrossRef] [PubMed]

3. Bellani, G.; Laffey, J.G.; Pham, T.; Fan, E.; Brochard, L.; Esteban, A.; Gattinoni, L.; Van Haren, F.; Larsson, A.; McAuley, D.F.; et al. Epidemiology, Patterns of Care, and Mortality for Patients with Acute Respiratory Distress Syndrome in Intensive Care Units in 50 Countries. JAMA 2016, 315, 788-800. [CrossRef] [PubMed]

4. Fan, E.; Del Sorbo, L.; Goligher, E.C.; Hodgson, C.L.; Munshi, L.; Walkey, A.J; Adhikari, N.K.J;; Amato, M.B.P.; Branson, R.; Brower, R.G.; et al. An official American Thoracic Society/European Society of Intensive Care Medicine/Society of Critical Care Medicine Clinical Practice Guideline: Mechanical Ventilation in Adult Patients with Acute Respiratory Distress Syndrome. Am. J. Respir. Crit. Care Med. 2017, 195, 1253-1263. [CrossRef]

5. Rackley, C.R.; MacIntyre, N.R. Low Tidal Volumes for Everyone? Chest 2019, 156, 783-791. [CrossRef]

6. Brower, R.G.; Lanken, P.N.; MacIntyre, N.; Matthay, M.A.; Morris, A.; Ancukiewicz, M.; Schoenfeld, D.; Thompson, B.T.; The National Heart, Lung, and Blood Institute ARDS Clinical Trials Network. Higher versus lower positive end-expiratory pressures in patients with the acute respiratory distress syndrome. N. Engl. J. Med. 2004, 351, 327-336.

7. Acute Respiratory Distress Syndrome Network; Brower, R.G.; Matthay, M.A.; Morris, A.; Schoenfeld, D.; Thompson, B.T.; Wheeler, A. Ventilation with lower tidal volumes as compared with traditional tidal volumes for acute lung injury and the acute respiratory distress syndrome. N. Engl. J. Med. 2000, 342, 1301-1308.

8. Writing Group for the PReVENT Investigators; Simonis, F.D.; Neto, A.S.; Binnekade, J.M.; Braber, A.; Bruin, K.C.M.; Determann, R.M.; Goekoop, G.J.; Heidt, J.; Horn, J.; et al. Effect of a Low vs. Intermediate Tidal Volume Strategy on Ventilator-Free Days in Intensive Care Unit Patients without ARDS: A Randomized Clinical Trial. JAMA 2018, 320, 1872-1880.

9. Talmor, D.; Sarge, T.; Malhotra, A.; O'Donnell, C.R.; Ritz, R.; Lisbon, A.; Novack, V.; Loring, S.H. Mechanical ventilation guided by esophageal pressure in acute lung injury. N. Engl. J. Med. 2008, 359, 2095-2104. [CrossRef]

10. Loring, S.H.; O’Donnell, C.R.; Behazin, N.; Malhotra, A.; Sarge, T.; Ritz, R.; Novack, V.; Talmor, D. Esophageal pressures in acute lung injury: Do they represent artifact or useful information about transpulmonary pressure, chest wall mechanics, and lung stress? J. Appl. Physiol. 2010, 108, 515-522. [CrossRef]

11. Malbrain, M.L.; Wilmer, A. The polycompartment syndrome: Towards an understanding of the interactions between different compartments! Intensive Care Med. 2007, 33, 1869-1872. [CrossRef] [PubMed]

12. Force, A.D.T.; Ranieri, V.M.; Rubenfeld, G.D.; Thompson, B.T.; Ferguson, N.D.; Caldwell, E.; Fan, E.; Camporota, L.; Slutsky, A.S. Acute respiratory distress syndrome: The Berlin Definition. JAMA 2012, 307, 2526-2533.

13. Baydur, A.; Behrakis, P.K.; Zin, W.A.; Jaeger, M.; Milic-Emili, J. A simple method for assessing the validity of the esophageal balloon technique. Am. Rev. Respir. Dis. 1982, 126, 788-791. [PubMed] 
14. Mojoli, F.; Iotti, G.A.; Torriglia, F.; Pozzi, M.; Volta, C.A.; Bianzina, S.; Braschi, A.; Brochard, L. In vivo calibration of esophageal pressure in the mechanically ventilated patient makes measurements reliable. Crit. Care 2016, 20, 1-9. [CrossRef] [PubMed]

15. Grieco, D.L.; Chen, L.; Brochard, L. Transpulmonary pressure: Importance and limits. Ann. Transl. Med. 2017, 5, 14. [CrossRef] [PubMed]

16. Olegard, C.; Sondergaard, S.; Houltz, E.; Lundin, S.; Stenqvist, O. Estimation of functional residual capacity at the bedside using standard monitoring equipment: A modified nitrogen washout/washin technique requiring a small change of the inspired oxygen fraction. Anesth. Analg. 2005, 101, 206-212. [CrossRef]

17. Malbrain, M.L.; Deeren, D.H. Effect of bladder volume on measured intravesical pressure: A prospective cohort study. Crit. Care 2006, 10, R98. [CrossRef]

18. Andrews, P.L.; Sadowitz, B.; Kollisch-Singule, M.; Satalin, J.; Roy, S.; Snyder, K.; Gatto, L.A.; Nieman, G.F.; Habashi, N.M. Alveolar instability (atelectrauma) is not identified by arterial oxygenation predisposing the development of an occult ventilator-induced lung injury. Intensive Care Med. Exp. 2015, 3, 1-12. [CrossRef]

19. Caironi, P.; Cressoni, M.; Chiumello, D.; Ranieri, M.; Quintel, M.; Russo, S.G.; Cornejo, R.; Bugedo, G.; Carlesso, E.; Russo, R.; et al. Lung opening and closing during ventilation of acute respiratory distress syndrome. Am. J. Respir. Crit. Care Med. 2010, 181, 578-586. [CrossRef]

20. Steinberg, J.M.; Schiller, H.J.; Halter, J.M.; Gatto, L.A.; Lee, H.M.; Pavone, L.A.; Nieman, G.F. Alveolar instability causes early ventilator-induced lung injury independent of neutrophils. Am. J. Respir. Crit. Care Med. 2004, 169, 57-63. [CrossRef]

21. Cressoni, M.; Cadringher, P.; Chiurazzi, C.; Amini, M.; Gallazzi, E.; Marino, A.; Brioni, M.; Carlesso, E.; Chiumello, D.; Quintel, M.; et al. Lung inhomogeneity in patients with acute respiratory distress syndrome. Am. J. Respir. Crit. Care Med. 2014, 189, 149-158. [CrossRef]

22. Gattinoni, L.; Carlesso, E.; Cressoni, M. Selecting the 'right' positive end-expiratory pressure level. Curr. Opin. Crit. Care 2015, 21, 50-57. [CrossRef]

23. Goligher, E.C.; Kavanagh, B.P.; Rubenfeld, G.D.; Adhikari, N.K.; Pinto, R.; Fan, E.; Brochard, L.J.; Granton, J.T.; Mercat, A.; Richard, J.C.M.; et al. Oxygenation response to positive end-expiratory pressure predicts mortality in acute respiratory distress syndrome. A secondary analysis of the LOVS and ExPress trials. Am. J. Respir. Crit. Care Med. 2014, 190, 70-76. [PubMed]

24. Amato, M.B.; Meade, M.O.; Slutsky, A.S.; Brochard, L.; Costa, E.L.; Schoenfeld, D.A.; Stewart, T.E.; Briel, M.; Talmor, D.; Mercat, A.; et al. Driving pressure and survival in the acute respiratory distress syndrome. $N$. Engl. J. Med. 2015, 372, 747-755. [CrossRef] [PubMed]

25. Costa, E.L.; Borges, J.B.; Melo, A.; Suarez-Sipmann, F.; Toufen, C., Jr.; Bohm, S.H.; Amato, M.B. Bedside estimation of recruitable alveolar collapse and hyperdistension by electrical impedance tomography. Intensive Care Med. 2009, 35, 1132-1137. [CrossRef] [PubMed]

26. Spina, S.; Capriles, M.; De Santis Santiago, R.; Florio, G.; Teggia-Droghi, M.; Grassi, L.; Hu, J.; Kelley, R.; Bittner, E.A.; Kacmarek, R.M.; et al. Development of a Lung Rescue Team to Improve Care of Subjects with Refractory Acute Respiratory Failure. Respir. Care 2020, 65, 420-426. [CrossRef]

27. Florio, G.; Ferrari, M.; Bittner, E.A.; De Santis Santiago, R.; Pirrone, M.; Fumagalli, J.; Droghi, M.T.; Mietto, C.; Pinciroli, R.; Berg, S.; et al. A lung rescue team improves survival in obesity with acute respiratory distress syndrome. Crit. Care 2020, 24, 1-11. [CrossRef]

28. Grune, J.; Tabuchi, A.; Kuebler, W.M. Alveolar dynamics during mechanical ventilation in the healthy and injured lung. Intensive Care Med. Exp. 2019, 7, 1-20. [CrossRef]

29. Guerin, C.; Papazian, L.; Reignier, J.; Ayzac, L.; Loundou, A.; Forel, J.M.; Investigators of the Acurasys and Proseva Trials. Effect of driving pressure on mortality in ARDS patients during lung protective mechanical ventilation in two randomized controlled trials. Crit. Care 2016, 20, 384. [CrossRef]

30. De Jong, A.; Cossic, J.; Verzilli, D.; Monet, C.; Carr, J.; Conseil, M.; Monnin, M.; Cisse, M.; Belafia, F.; Molinari, N.; et al. Impact of the driving pressure on mortality in obese and non-obese ARDS patients: A retrospective study of 362 cases. Intensive Care Med. 2018, 44, 1106-1114. [CrossRef]

31. Fuller, B.M.; Page, D.; Stephens, R.J.; Roberts, B.W.; Drewry, A.M.; Ablordeppey, E.; Mohr, N.M.; Kollef, M.H. Pulmonary Mechanics and Mortality in Mechanically Ventilated Patients without Acute Respiratory Distress Syndrome: A Cohort Study. Shock 2018, 49, 311-316. [CrossRef] [PubMed] 
32. Dellamonica, J.; Lerolle, N.; Sargentini, C.; Beduneau, G.; Di Marco, F.; Mercat, A.; Richard, J.C.; Diehl, J.L.; Mancebo, J.; Rouby, J.J.; et al. Accuracy and precision of end-expiratory lung-volume measurements by automated nitrogen washout/washin technique in patients with acute respiratory distress syndrome. Crit. Care 2011, 15, R294. [CrossRef] [PubMed]

33. Fumagalli, J.; Berra, L.; Zhang, C.; Pirrone, M.; Santiago, R.R.S.; Gomes, S.; Magni, F.; Dos Santos, G.A.B.; Bennett, D.; Torsani, V.; et al. Transpulmonary Pressure Describes Lung Morphology during Decremental Positive End-Expiratory Pressure Trials in Obesity. Crit. Care Med. 2017, 45, 1374-1381. [CrossRef]

34. Fumagalli, J.; Santiago, R.R.S.; Droghi, M.T.; Zhang, C.; Fintelmann, F.J.; Troschel, F.M.; Morais, C.C.A.; Amato, M.B.P.; Kacmarek, R.M.; Berra, L.; et al. Lung Recruitment in Obese Patients with Acute Respiratory Distress Syndrome. Anesthesiology 2019, 130, 791-803. [CrossRef] [PubMed]

35. Regli, A.; Pelosi, P.; Malbrain, M. Ventilation in patients with intra-abdominal hypertension: What every critical care physician needs to know. Ann. Intensive Care 2019, 9, 52. [CrossRef] [PubMed]

36. Krebs, J.; Pelosi, P.; Tsagogiorgas, C.; Alb, M.; Luecke, T. Effects of positive end-expiratory pressure on respiratory function and hemodynamics in patients with acute respiratory failure with and without intra-abdominal hypertension: A pilot study. Crit. Care 2009, 13, R160. [CrossRef]

(C) 2020 by the authors. Licensee MDPI, Basel, Switzerland. This article is an open access article distributed under the terms and conditions of the Creative Commons Attribution (CC BY) license (http://creativecommons.org/licenses/by/4.0/). 